\title{
Perbaikan Musala dan Mengajar Ngaji untuk Meningkatkan Kenyamanan Ibadah dan Mengaji
}

\author{
Fuad Indra Kusuma*, Moh. Edo Abdulloh, Fani Maulana \\ Universitas Negeri Malang, Jl. Semarang No. 5 Malang, Jawa Timur, Indonesia \\ *Penulis korespondensi, Surel: fuad.indra.ft@um.ac.id
}

Paper received: 2-11-2021; revised: 17-11-2021; accepted: 23-11-2021

\begin{abstract}
It is common that a mosque or prayer room is very important for Muslims, where the mosque or prayer room is used as a place of worship for Muslims such as praying, reading the Koran and others. The construction of a mosque or prayer room is a gift from Allah, because the mosque is the house of Allah on earth. The mosque is the most noble, most sacred house that Allah has placed on earth. Therefore, we as Muslims should clean, care for, and renovate if there is something that needs to be repaired. The 2021 UM KKN group in Donomulyo village took the initiative to renovate the prayer room in Mulyosari hamlet, Donomulyo village, Donomulyo District, Malang Regency. With this renovation activity, it is hoped that it will become a medium for KKN friends in Donomulyo village and the surrounding community as well as to gather or take care of the prayer room that is there, because there are several things that need to be repaired in the prayer room, moreover, the location targeted by the community service friends it's far from the crowds or the city. From there, the Donomulyo Village Community Service Group in 2021 took the initiative to renovate the prayer room and also help teach the cabai rawit brothers who were there.
\end{abstract}

Keywords: mosque renovation; teaching the koran

\begin{abstract}
Abstrak
Sudah menjadi hal umum bahwa sebuah masjid atau musala menjadi hal yang sangat penting bagi umat islam, yang mana masjid atau musala digunakan sebagai tempat ibadah umat islam seperti melaksanakan sholat, mengaji dan lain-lain. Dibangunnya sebuah masjid atau musala itu merupakan salah satu anugerah dari allah, karena masjid merupakan rumah allah di muka bumi. Masjid adalah rumah yang paling mulia, yang paling suci yang allah letakkan di muka bumi. Oleh sebab itu seyogyanya kita sebagai umat islam untuk membersihkan, merawat, serta merenovasi apabila ada yang perlu diperbaiki. Kelompok KKN UM 2021 di desa Donomulyo berinisiatif renovasi musala yang ada di dusun Mulyosari, desa Donomulyo, Kecamatan Donomulyo, Kabupaten Malang. Dengan adanya kegiatan renovasi ini diharapkan bisa menjadi media bagi temen-temen KKN desa Donomulyo dengan masyarakat sekitar sekaligus untuk merawat atau merawat musala yang ada disana, karena ada beberapa hal yang perlu diperbaiki pada musala tersebut, terlebih, lokasi yang dituju oleh temen-temen KKN ini jauh dari keramaian atau kota. Dari situlah kelompok KKN desa Donomulyo tahun 2021 berinisiatif untuk renovasi musala serta juga ikut membantu mengajar adikadik caberawit yang ada disana.
\end{abstract}

Kata kunci: renovasi musala; mengajar mengaji

\section{Pendahuluan}

Musala merupakan tempat atau rumah kecil yang menyerupai masjid dan berfungsi untuk shalat maupun mengaji bagi umat muslim. Tidak hanya itu saja, musala juga dapat digunakan sebagai pusat kegiatan masyarakat. Mulai dari kegiatan rapat, tempat pengumuman desa, istighosah, dan sebagainya. Dengan banyaknya kegiatan yang bisa dilakukan di musala, musala sendiri dituntut untuk selalu bersih dan nyaman agar kegiatan yang dilakukan di musala dapat berjalan dengan baik dan nyaman. Maka dari itu untuk mendapatkan musala 
yang bersih dan nyaman perlunya dilakukan perbaikan secara rutin agar musala dapat terjaga seperti semestinya.

Seperti halnya dengan musala Al-Ikhlas dusun Mulyosari, Donomulyo. Dimana musala tersebut berada di daerah pedalaman desa Donomulyo yang setiap hari digunakan untuk shalat berjamaah dan mengaji bagi anak-anak sekitaran dusun Mulyosari. Caberawit yang ada disana sangat memiliki antusias yang tinggi dalam mengikuti kegiatan belajar mengajar mengaji serta bermain sambil belajar.

Musala Al-Ikhlas sendiri masih memiliki beberapa permasalahan. Mulai dari permasalahan atap jebol, pencahayaan redup, karpet yang berantakan, pintu kamar mandi rusak, dan masih banyak lagi. Dengan banyaknya permasalahan tersebut membuat kegiatan yang dilakukan di musala Al-Ikhlas menjadi kurang nyaman. Jika dibiarkan hal ini akan berdampak pada kegiatan yang dilakukan di musala tersebut. Mulai dari murid mengaji yang semakin berkurang, kegiatan sholat berjamaah yang jarang, dan lain sebagainya.

Oleh sebab itu, perlu dilakukannya program perbaikan terhadap musala Al-Ikhlas. Dengan dilakukannya perbaikan, diharapkan kegiatan yang dilakukan di musala dapat berjalan dengan lancar dan nyaman. Tidak hanya itu saja, kegiatan perbaikan musala ini juga dibarengi dengan program mengajar ngaji untuk anak-anak sekitaran dusun Mulyosari. Hal ini bertujuan untuk mengimplementasikan ilmu yang selama ini dimiliki mahasiswa untuk dibagikan kepada anak-anak generasi muda. Kedua program ini merupakan program kerja dari kegiatan Kuliah Kerja Nyata (KKN) Membangun Desa Universitas Negeri Malang kelompok Desa Donomulyo, Kecamatan Donomulyo Kabupaten Malang.

Dengan diadakannya program diatas, diharapkan kegiatan masyarakat dusun Mulyosari khususnya RT 18 dapat berjalan dengan baik. Serta kegiatan pembelajaran mengaji dapat memotivasi dan memberikan ilmu bagi anak-anak sekitaran dusun mulyosari agar kedepannya tetap selalu mengamalkan ilmu mengaji dengan rutin, baik, dan benar.

\section{Metode}

\subsection{Tahapan}

Tahapan untuk tahapan pelaksanaan program perbaikan musala dan mengajar ngaji akan disajikan pada flowchart Gambar 1.

1. Pengajuan izin ke kepala desa dan ketua RT

Melakukan pengajuan izin perbaikan musala Al-Ikhlas ke Kepala Desa dan Ketua RT.

\section{Pengajuan dana untuk pembelian material}

Setelah mendapatkan persetujuan dari Kepala Desa dan Ketua RT, maka langkah selanjutnya adalah mengajukan dana untuk melaksanakan program perbaikan. Dana tersebut digunakan untuk pembelian material, mulai dari asbes internal, paku, cat, dsb. 


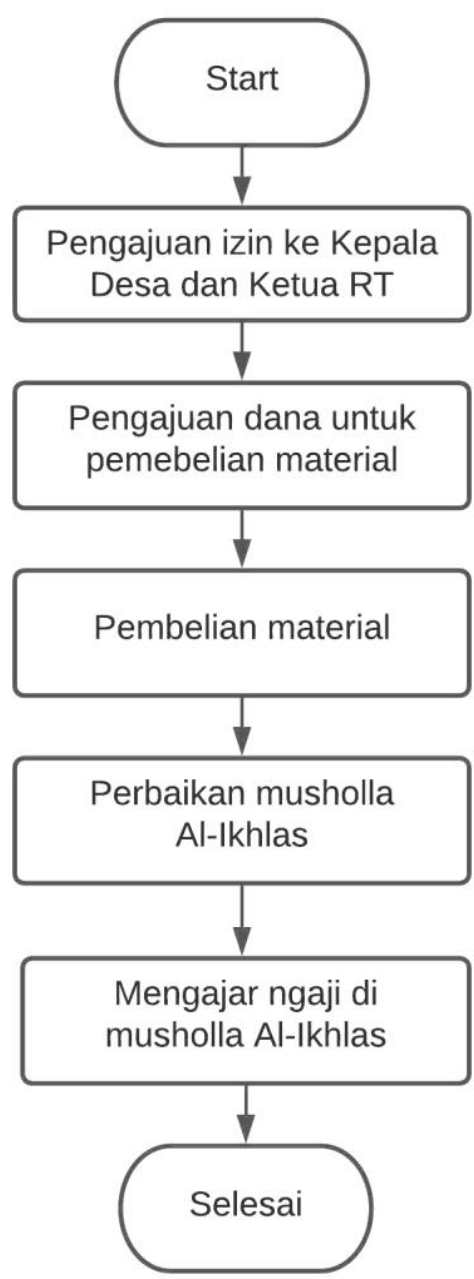

\section{Gambar 1. Tahapan Pelaksanaan Program Perbaikan Musala dan Mengajar Ngaji}

\section{Pembelian Material}

Setelah pengajuan dana telah disetujui, maka langkah selanjutnya adalah melakukan pembelian material yang telah direncanakan dengan mengunjungi toko sesuai material yang dibutuhkan.

\section{Perbaikan musala}

Setelah mendapatkan seluruh material, maka tahap selanjutnya adalah proses eksekusi yaitu dengan melakukan perbaikan musala Al-Ikhlas. Perbaikan yang dilakukan meliputi perbaikan asbes internal dan pintu kamar mandi, penataan karpet dan gudang musala, penggantian lampu musala, dan kegiatan kecil lainnya.

\section{Mengajar Ngaji}

Setelah musala telah diperbaiki dan dirasa sudah nyaman. Maka tahap selanjutnya adalah mengajar ngaji untuk anak-anak sekitaran dusun mulyosari. 


\subsection{Waktu dan Tempat Pelaksanaan}

Pelaksanaan program perbaikan musala dan mengajar ngaji berada di musala Al-Ikhlas yang beralamat di Dusun Mulyosari Rt 18 Rw 07, Desa Donomulyo, Kecamatan Donomulyo pada tanggal 12-14 November 2021.

\subsection{Rincian Kegiatan}

Kegiatan ini dilaksanakan selama 3 hari pada hari Jum'at sampai Minggu, 12-14 November 2021. Untuk detail pelaksanaannya dapat dilihat pada Tabel 1 di bawah ini.

Tabel 1. Detail Pelaksanaan Program Perbaikan Musala dan Mengajar Ngaji

\begin{tabular}{|c|c|c|c|}
\hline No & Kegiatan & Waktu & Keterangan \\
\hline \multicolumn{4}{|r|}{ 12-Nov-21 } \\
\hline 1 & Persiapan & $16.00-17.00$ & $\begin{array}{l}\text { Seluruh anggota KKN meninjau permasalahan yang ada } \\
\text { pada musholla Al-Ikhlas }\end{array}$ \\
\hline 2 & Pembukaan & $18.00-18.15$ & $\begin{array}{l}\text { Seluruh anggota KKN memperkenalkan diri masing- } \\
\text { masing kepada murid-murid ngaji di musholla Al-Ikhlas }\end{array}$ \\
\hline 3 & Mengajar Ngaji & $18.16-19.00$ & $\begin{array}{l}\text { Seluruh anggota KKN mulai mengajar ngaji murid-murid } \\
\text { ngaji }\end{array}$ \\
\hline & & & 13-Nov-21 \\
\hline 4 & Membeli Material & 09.00-10.00 & $\begin{array}{l}\text { Anggota perkap membeli material untuk kebutuhan } \\
\text { perbaikan musholla }\end{array}$ \\
\hline \multirow{5}{*}{5} & \multirow{4}{*}{ Pelaksanaan } & $10.00-12.00$ & $\begin{array}{l}\text { Beberapa anggota KKN melakukan penggantian asbes } \\
\text { internal musholla }\end{array}$ \\
\hline & & $12.00-13.00$ & Istirahat \\
\hline & & $13.00-14.00$ & Membersikan Atau menyapu bagian dalam musholla \\
\hline & & $14.00-15.00$ & Merapikan karpet, kabel, gudang \\
\hline & & $15.00-17.00$ & Membersikan bagian luar musholla \\
\hline 6 & Mengajar Ngaji & $18.00-19.00$ & $\begin{array}{l}\text { Mengajar ngaji, motivasi tentang pendidikan dan ngaji } \\
\text { 14-Nov-21 }\end{array}$ \\
\hline 7 & Mengajar Ngaji & $18.00-19.00$ & Memantabkan ilmu baca Al-Quran \\
\hline 8 & Selesai & & \\
\hline
\end{tabular}

\section{Hasil dan Pembahasan}

Berdasarkan rencana perbaikan musholla dan mengajar ngaji yang telah dilaksanakan, telah mendapatkan hasil yang dimana untuk perbaikan musholla telah disajikan pada Tabel 2 dibawah ini.

Tabel 2. Hasil Perbaikan Musholla

\begin{tabular}{ccl}
\hline No Sebelum & Sesudah & \multicolumn{1}{c}{ Ket. } \\
\hline 1 & & $\begin{array}{l}\text { Penggantian asbes internal } \\
\text { yang bolong menjadi as bes baru }\end{array}$ \\
& & \\
\hline
\end{tabular}




\begin{tabular}{lll}
\hline No Sebelum & \multicolumn{1}{c}{ Sesudah } & \multicolumn{1}{c}{ Ket. } \\
\hline 2 & & \\
&
\end{tabular}

Sementara itu hasil dari pelaksanaan mengajar ngaji ialah:

1. Memberikan motivasi untuk selalu menuntut ilmu untuk bidang agama maupun akademik

2. Memberikan arahan tentang memahami tajwid Al-Quran.

\section{Simpulan}

Beberapa kesimpulan yang didapat dari program perbaikan musholla dan mengajar ngaji ialah: (1) Setelah dilakukan perbaikan musholla didapatkan bahwa fasilitas yang sebelumnya rusak sudah dapat digunakan dengan baik sehingga kenyamanan telah ditingkatkan, (2) Setelah dilakukannya mengajar ngaji kepada anak-anak sekitaran dusun Mulyosari didapatkan bahwa anak-anak lebih memahami tentang tajwid yang ada pada Al- 
Quran, (3) Setelah diberikan motivasi tentang pentingnya mengaji, anak-anak lebih banyak yang berdatangan untuk mengaji dari pada biasanya, (4) Dari program kegiatan perbaikan musholla dan mengajar ngaji ini, mahasiswa KKN MBKM UM dapat menjalankan sebuah program dengan baik dan terorganisir.

\section{Ucapan Terima Kasih (Opsional)}

Penulis menyampaikan terima kasih kepada pihak yang terlibat, yaitu: Kepala Desa Donomulyo beserta jajarannya, dan warga Desa Donomulyo yang telah memberi dukungan dan bantuan terhadap keberlangsungan program pengabdian masyarakat ini, yaitu program renovasi dan mengajar mengaji caberawit.

\section{Daftar Rujukan}

Ahmadi, D. (2005). Interaksi Simbolik: Suatu Pengantar.

Mead, G. (1934). Mind, Self and Society. Chicago: The University of Chicago Press.

Pratama, A. H. (2017). Perkembangan Pengguna Internet di Indonesia Tahun 2016 Terbesar di Dunia.

Griffin, E. A. (2003). A First Look at Communication Theory, 5th edition. New York City: McGraw-Hill.

James.P., S. (1980). The Ethnographic Interview. New York City: Holt Renehart and Winston.

Sosiologis.com. (2017). Interaksi Sosial: Pengertian dan Contohnya. 